\title{
PCR Revisited! - A Review
}

\author{
Samyukta Reddy ${ }^{1 *}$, Lokesh Papaiah ${ }^{2}$, Sushma Reddy ${ }^{2}$, Suchitra SR ${ }^{2}$ and Divya Uppala ${ }^{3}$ \\ ${ }^{1}$ Department of Oral Pathology, MA Rangoonwala Dental College, India \\ ${ }^{2}$ Department of Oral Pathology, Vydehi Institute of Dental Sciences, India \\ ${ }^{3}$ Department of Oral Pathology, GITAM dental College, India
}

Submission: August 05, 2017; Published: August 10, 2017

*Corresponding author: Samyukta Reddy, Department of Oral Patholgy, MA Rangoonwala Dental College, Pune, India, Tel: +919881912922; Email: sudarshan19samyukta@gmail.com

\begin{abstract}
Deoxyribonucleic acid (DNA) is the chemical basis of life and heredity. The analysis of DNA, RNA and proteins obtained from diagnostic specimens, is currently revolutionizing the practice of surgical pathology. PCR is an emerging tool in diagnostic molecular pathology and also a useful research technique, which greatly amplifies a specific sequence of DNA or cDNA. PCR forms the basis of much of diagnostic and research medicine. Amplification of both DNA and RNA sequences can be performed using the PCR. PCR is an emerging tool in diagnostic molecular pathology and also a useful research technique, which greatly amplifies a specific sequence of DNA or cDNA. PCR gives as much of a particular DNA needed and hence is a very useful tool for a molecular biologist.
\end{abstract}

\section{Introduction}

DNA is organised into genes which are fundamental units of genetic information. Genes control protein biosynthesis through ribonucleic acid (RNA). DNA is composed of two strands of repeating units of deoxyribo nucleotides, arranged in a double helix and held by hydrogen bonds. During replication, the two strands of DNA duplex are unwound and separated. Two new strands, complementary to the original strands are synthesised by semi conservative replication in presence of the enzyme DNA polymerase [1].

The era of the pathologist relying entirely on the examination of tissue sections stained by histo chemical methods is gradually being replaced by advanced immunologic and molecular techniques (i.e. analysis of DNA, RNA or protein structure or function) augment the process by which complicated infectious, inflammatory, metabolic and neoplastic diseases are diagnosed and classified [2]. This article provides a very brief insight into the PCR, its constituents and applications to enhance the knowledge of a general dentist.

\section{History}

Although DNA as first isolated in 1869 by Johann Friedrich Miescher, its structure was not known until 1953, when Watson and Crick published evidence of the double helix [3].

The investigation of an organism's genome was greatly enhanced during 1970s with the development of recombinant
DNA technology [3]. This technique allows for $\mathrm{n}$ vivo replication of genomic DNA regions that are covalently linked with bacterial plasmid or virus clones. In 1985-86, at Cetus Corporation in USA, researchers developed an in vitro method for amplification of DNA fragments, referred to as the polymerase chain reaction (PCR). The idea for PCR is credited to Kary Mullis et al. [4], who along with five other researchers demonstrated that oligonucleotide primers could be used specifically to amplify specific segments of genomic DNA or cDNA. This method was first proposed in early 1970s by H. Ghobind Khorana et al. [5] and his colleagues as a strategy to lessen the labour involved in chemical synthesis of genes.

Khorana's ideas were soon forgotten and the technique was independently conceived 15 years later, given its present name and put into practice by Mullis, who described in vitro amplification of single-copy mammalian genes using the Klenow fragment of Echerichia coli DNA polymerase I [6]. Since then PCR has transformed the way DNA analysis is carried out in both research and clinical laboratories.

Since the first description of a practical DNA amplification process many refinements have been described and automatic thermal cyclers have become standard laboratory equipment. PCR is now an essential tool for many biologists and the standard protocols are very simple and user friendly. The exponential amplification process provides nano gram quantities of 
essentially identical DNA molecules starting from a few copies of a target sequence. The amplified material (the PCR amplicon) is available in sufficient quantity to be identified by size analysis, sequencing or by probe hybridisation.

\section{The Basic Methodology}

In the simplest form, PCR is a chemical; as opposed to biological, method of greatly increasing the concentration of a specific nucleic acid sequence relative to that of other nucleic acid sequence in the reaction mixture [5]. Typical reasons for amplifying particular gene sequences are to determine the presence or absence of the sequence, or chromosome translocation, to determine whether a mutational hotspot contains a disease-related mutation or to study clonality of rearranged antigen receptor genes in lymphocyte populations.

\section{The essential components of the reaction are}

The template DNA: Template DNA containing genomic DNA or cDNA sample from patient can be used in single or doublestranded form [6].

Oligonucleotide primers: A pair of synthetic oligonucleoides should be short, single stranded, and complementary to opposite strands of the flanking regions of the fragment of interest [6].

Thermo stable DNA polymerase: A thermo stable DNA polymerase, which can withstand the denaturation temperatures (94-95 oc), is essential to catalyze the template dependent synthesis of DNA. Though a wide variety of enzymes are now available but for routine PCRs, Taq polymerase is used commonly [7].

Deoxynucleoside triphoshates (dNTPs): Standard PCRs contain equimolar concentrations of dNTP, dTTP, dATP, and dGTP (200-250 $\mu$ M each) [7].

Divalent cations: Free divalent cations are needed for the activity of thermo stable polymerases [8].

Buffer to maintain $\mathbf{p H}$ : The $\mathrm{pH}$ of reaction mixture is adjusted to 8.3-8.8 at room temperature for standard PCR [6].

Monovalent cations: $50 \mathrm{mM}$ of $\mathrm{KCl}$ is used in standard PCR for amplification of DNA segments more than 500base pairs in length. But it has been shown that elimination of $\mathrm{KCl}$ is beneficial [8].

Others: Some researchers have reported that the efficiency of reaction is increased by inclusion of $10 \%$ dimethyl sulfoxide (DMSO) in the Taq polymerase buffer [9].

\section{Procedure}

DNA or RNA suitable for PCR analysis can be obtained from most of tissue sources, including fresh or frozen unfixed tissue, cytology smears, stained sections, blood films and body fluids like saliva also. DNA extracted from formalin fixed paraffin wax embedded tissues can also be used for amplification by PCR.
DNA or RNA sequence to be amplified is identified and specific oligonucleotide primers, complementary to sequences in opposite strands are designed. The amplification can be conveniently performed in a DNA thermal cycler. Amplification of the target sequence is achieved by a repetitive series of cycles involving three steps:

a) Denaturation of the template by heat,

b) Annealing of the oligonucleotide primers to single stranded target sequences and

c) Extension of the annealed primers by thermostable DNA polymerase.

\section{Analysis of the PCR products}

The basic analysis of PCR products is based on the fact that double-stranded DNA molecules migrate through the gels on the basis of their size; larger products migrate more slowly than smaller ones. The simplest methods of analysing the PCR products are agarose gel electrophoresis or polyacrylamide gel electrophoresis, followed by ethidium bromide staining and viewing under UV illumination. The choice of the gel depends on the size and resolution required. For larger products (300bp and larger) agarose gels are more convenient and use less toxic reagents. If smaller fragments must be accurately sized, then polyacrylamide gels are required [10].

Gene scanning is a method that uses fluorescently-labelled primers and product analysis on an automated sequencing type gel. Results appear as plots of fluorescence against time that can be used to size products in comparison with control products of known size. This is performed in order to size products accurately and to quantify product yield.

\section{Variations on the basic PCR}

\section{Real time PCR}

Quantitative PCR: PCR amplifications have been performed with sufficient reproducibility to provide a quantitative estimate of DNA templates. The relative amount of the fragment of interest is determined by comparison with a standard generated by a second primer pair that is included in the same reaction.

Multiplex PCR: Multiplex PCR (M-PCR) is the simultaneous detection of more than one target sequence. M-PCR is the simultaneous amplification of more than one target sequence in a single reaction tube using more than one primer pair.

In-cell PCR: All the in-cell PCR techniques attempt to create double-stranded or singles tranded DNA/cDNA amplicons within the cell, which can either be detected directly or following an ISH step.

In-situ PCR: In-situ detection of polymerase chain reaction (PCR)-amplified DNA in intact cells was first described by Haase et al. in $1990[11,12]$. 
RNA PCR: RNA can also be used as template for PCR following reverse transcription. This technique is useful for the study of expressed gene sequences and retroviruses.

\section{PCR from Incomplete DNA Sequence Information}

Frequently the DNA sequence of a region to be analyzed is not entirely or exactly known. In these cases PCR may be applied if there is sequence information from flanking regions or related DNA templates.

\section{Applications of PCR}

\section{Diagnostic Applications of PCR}

a) Detecting pathogens using genome-specific primer pairs in clinical samples.

b) Detection of viral pathogens and other micro-organisms which persist in low levels in infected cells and are difficult to be identified by routine methods.

c) Quantitative Real-Time can be used to detect viral genomes such as HIV or HPV.

d) Diagnosis of genetic disorders such as phenyl ketonuria, haemophilia, sickle cell anaemia, thalassemia.

e) Identification of genetic mutations like deletions, insertions and point mutations.

f) Screening specific genes for unknown mutations - The PCR technique of single strand conformational polymorphism (SSCP) is one of the most widely used methods for detecting single base pair changes in genomic DNA.

g) Identification and analysis of mutations in eukaryotic DNA

i. DNA deletions and insertions can be detected by a change in the size of the PCR product.

ii. Failure to produce any PCR fragment indicates that the primer is found binding to an area of deletion.

iii. Mutations can be identified by hybridizing PCRgenerated DNA fragments to radioactively labelled RNA probes and digesting the DNA-RNA complexes with RNAse A. Digestion will occur if the complex contains any mismatches.

iv. Localization of mutations has also been achieved by examining PCR products using denaturing gradient gel electrophoresis (DGGE).This separates about $50 \%$ of DNA strands $1000 \mathrm{bp}$ in length that have single base changes.

h) Detection of amplified oncogenes using differential PCR.

i) Gene polymorphisms.

j) Gene expression

i. Growth factors during wound healing ii. Gene expression during embryogenesis.

iii. Quantitation of gene expression in various organs, e.g. dystrophin.

\section{Laboratory applications of PCR}

a) Sub cloning DNA targets using PCR: There are numerous situations in which a specific DNA segment needs to be cloned into a plasmid vector.

b) Mutagenesis - technique of changing the base sequence of DNA to test its effect on gene or DNA function Mutagenesis can be carried out in vitro or in vivo. In vitro, a gene may be cloned and single-stranded recombinant DNA recovered. A mutagenic oligonucleotide primer is then designed which has a mutation site (a single base difference), coding for the intended mutation at specific site. This is then allowed to prime new DNA synthesis to create a complementary fulllength sequence containing the desired mutation. The new DNA is then used to transform cells and to study the effects of the mutation. PCR-mediated in vitro mutagenesis technique uses to advantage the elevated error rate of Taq polymerase in the presence of $\mathrm{MnCl}_{2}$ and high $\mathrm{MgCl}_{2}$.

c) DNA sequencing - usually involves enzymatic DNA synthesis in the presence of base-specific dideoxynucleotide (ddNTPs) chain terminators. The reactions are carried out using one or more labelled nucleotides and a sequencing primer. In addition, the mixture contains the base-specif|c ddNTPs, which differ from normal dNTPs (lack a hydroxyl group at the 30 and 20 -carbon position). When incorporated into a growing DNA chain, the ddNTP cannot participate further in phosphor diester bonding at its 30 carbon and therefore causes termination of chain synthesis beyond that point in the chain. The difference from conventional PCR is that only one primer is used and ddNTPs are present in the reaction mixture. The product will accumulate linearly rather than exponentially due to the presence of only one primer [12].

d) It is also possible to prepare unique gene fusions using consecutive PCR reactions. This technique is sometimes called PCR-mediated gene SOEing (splicing by overlap extension).

e) Generation of specific sequences of cloned doublestranded DNA probes for In-situ Hybridization.

f) Generation of libraries from small amounts of mRNA and hence establish cDNA libraries.

g) Generation of large amounts of template DNA for sequencing.

h) To amplify unknown DNA sequences that lie outside the boundary of known sequences (inverse PCR). 
i) The Human Genome Project - PCR has been an important tool in both mapping (physical and genetic) and sequencing aspect of human genome project [11].

j) Evolutionary Studies - nucleoside sequence in DNA provides data for reconstruction of evolutionary patterns of species and also about the virus phylogeny. PCR has also been used to amplify mitochondrial DNA sequences from different human populations and hence permitting the construction phylogenetic trees. These phylogenetic trees have confirmed the african origin of humans [10].

\section{Applications in forensic sciences}

The ability of PCR to detect DNA polymorphisms has made it an important tool in forensic biology. All forms of biological evidence collected from the crime scene or any individual can be analyzed using a PCR.

Using restriction fragment length polymorphism (RFLP) analysis, DNA specific to particular individuals can be obtained. But this technique requires more than 50ng of DNA which is not degraded. This has been overcome by use of PCR. PCR has allowed the genotyping of biological evidence found at the crime scene by amplifying polymorphic sequences. Analysis of variable number tandem repeats (VNTRs) using PCR is less time consuming as compared to southern blotting. In addition, PCR can analyze minute quantities of degraded DNA unlike the southern blotting which requires large amounts of intact, high molecular size DNA [8].

\section{Conclusion}

PCR is perhaps the most important innovation in modern techniques in molecular biology since the introduction of DNA sequencing and the use of plasmids and restriction enzymes. A large range of sample types may be examined, including forensic or paleontological specimens. PCR is now widely used in a vast variety of disciplines such as gene cloning, mRNA quantification, DNA sub cloning and site directed mutagenesis, diagnostic techniques in forensic and clinical studies, as well as in molecular evolution and population genetics. Various modifications of PCR have allowed for vast expansion of the diagnostic and research uses. The development of fluorogenic probes and real time quantitative PCR allows greater automation of the technique without the requirement of subsequent detection steps.

\section{References}

1. Harvey RA (2013) Lippincott's illustrated Review's. In: Harvey RA, Cornelissen CN, Fisher BD (eds.), ( $3^{\text {rd }}$ edn), Microbiology, Lippincott Williams \& Wilkins, Philadelphia, Pennsylvania, United States.

2. Richard CJ, Troy ED, Greenspan S, Regezi JA (2001) Advanced diagnostic methods in oral and maxillofacial pathology. Part I: Molecular methods. Oral Surg Oral Med Oral Pathol Oral Radiol Endod 92(6): 650-669.

3. O'leary JJ, Engles K, Dada MA (1997) The polymerase chain reaction in pathology J Clin Pathol 50(10): 805-810.

4. Saiki RK, ScharfS, Faloona F, Mullis KB, Horn GT, et al. (1985) Enzymatic amplification of beta-globin genomic sequences and restriction site analysis for diagnosis of sickle cell anemia. Science 230(4732): 13501354.

5. Kleppe K, van de Sande JH, Khorana HG (1970) Polynucleotide ligasecatalyzed joining of deoxyribo-oligonucleotides on ribopolynucleotide templates and of ribo-oligonucleotides on deoxyribopolynucleotide templates. Proc Natl Acad Sci USA 67(1): 68-73.

6. Sambrook, Russel (2000) Molecular cloning Part II. In: Sambrook, Russel (eds.), ( $3^{\text {rd }}$ edn), Cold Spring Harbor Laboratory Press, United states, p. 2344.

7. Erlich HA (1990) PCR Technology-Principles and Applications for DNA amplification. Journal of Basic Microbiology 30(10): 736.

8. Chien A, Edgar DB, Trela JM (1976) Deoxyribonucleic acid polymerase from the extreme thermophile Thermus aquaticus. J Bacteriol 127(3): 1550-1557.

9. Bloch W (1991) A biochemical perspective of the polymerase chain reaction. Biochemistry 30(11): 2735-2747.

10. Richard KW, Chia C, Nebojs A, James B, Leroy H (1989) Development of an automated procedure for fluorescent DNA sequencing. Genomics 6(4): 626-634.

11. Gibbs RA (1990) DNA amplification by the polymerase chain reaction. Anal Chem 62(13): 1202-1214.

12. Chawla HS (2009) Introduction to plant biotechnology. In: Chawla HS (ed.), ( $3^{\text {rd }}$ edn), CRC Press, Boca Raton, Florida, United States, p. 744.

\footnotetext{
Your next submission with Juniper Publishers will reach you the below assets

- Quality Editorial service

- Swift Peer Review

- Reprints availability

- E-prints Service

- Manuscript Podcast for convenient understanding

- Global attainment for your research

- Manuscript accessibility in different formats

( Pdf, E-pub, Full Text, Audio)

- Unceasing customer service

Track the below URL for one-step submission https://juniperpublishers.com/online-submission.php
} 